\title{
Surface pressure effect on rivet-connected I-corner plates exposed to axial and flexural loadings
}

\section{Murat Yavuz ${ }^{*}$}

'Department of Mechanical Engineering, İzmir Democracy University, İzmir, 35 I 40, Turkey

Orcid: M.M. Yavuz(0000-0002-5892-0075)

Abstract: In this study, the stress and deformation behaviour of two l-corner plates with rivet connection in bending and tension were investigated. Pure bending and axial tension were applied at the end edge as the boundary condition and fixed support was defined at the other end edge of the plates. The finite element method was used. A suitable validation study was conducted, and its results were compared with the literature cases. A surface pressure was applied to the rounded I-corner. The results are shown in the form of the stress concentration factor. The time-dependent response of applied pressure was also performed to observe the dynamic behaviour. The stresses in the plates occurred at the calculated values and as a result the stress concentration factor was about I.0. The stress concentration factor of the plate in the rivet region is $I=0.2$ and in the rivets goes up to 5.0. The results are discussed in detail.

Keywords: Rivet connection, bending, I-corner, plates, stress concentration

\section{Introduction}

Plate joints have many uses in engineering. Various studies on the examination and development of their connections are constantly ongoing. The most important feature in the use of plates is that it performs lower weight mechanical functions and support thanks to a high surface area capacity compared to thickness. However, their thin structure creates a disadvantage in terms of strength and causes stress concentrations to have a greater effect on the joints. In the literature, it has been determined that high stress concentrations occur at the rivet joints of the plates and the cracks starting at these stress concentrated locations cause fractures. Moreno and Valiente [1] prepared a model to determine the stress intensity factor in riveted steel beam including crack. İbrahim and Pettit [2] made a review study for understanding uncertainties of bolted joints and fasteners and mentioned that joints have complex mechanical behaviour and contain nonlinear properties. Bedair and Eastaugh [3] investigated riveted splice joints. The secondary bending involved has a dominant effect on maximum tensile and compressive stresses in joints up to $39 \%$. Sadowski et al. [4] investigated the damage on simple rivet, simple adhesive bonded and hybrid adhesive-riveted joint under tension. Aluminium plates, rivets and cohesive layers were included into the FEM analysis. The hybrid riveted joint has the best per- formance compared to bonded and simple joints. D'Aniello et al. [5] considered shear behaviour of rivets in steel connections. Secondary tensile effect, which has a dominant effect, was observed. Longer unsymmetrical joints were recommended which had more resistance to bending effects. Díaz et al. [6] investigated modelling of joints in steel frames and prepared a review of fatigue effects. The used models had consistent moment-rotation curve, however, sensitivity decreased when an axial load was applied. Kumar et al. [7] investigated riveted lap joints having different number of rivets and rows. Linear behaviour was observed when large numbers of rivets were used, and when the number of rivets decreased, the joint showed non-linear behaviour. Bedair [8] studied on strength of spliced joints. Secondary bending caused large stiffness variation and affected maximum tensile and compressive stresses. Huang et al. [9] used a short pipe rivet for connecting metal sheets. The considered rivet heights, diameters, end angle and rivet wall thickness showed that lap joints had the greatest static strength values, but their failure occurred at less displacement. Skorupa et al. [10] analysed fatigue life of riveted lap joints used in aluminium airframe. The interference fit in connection could prevent notch effect. Kafie-Martinez et al. [11] investigated crack growth behaviour of riveted lap joints. The rivet temperature was included during fastening process. The 
used thick plate joining showed higher fatigue crack grow rate and less residual stress effect. Song et al. [12] investigated rivet connection of truss beams under bending. Two types of failure were observed, and one occurred in the rivet. Nejad et al. [13] studied fatigue crack growth of riveted joints in Al-2024 plates and observed the cracks initiated at the sheet joint. Zhang et al. [14] used self-piercing riveted joints in titanium plates and observed the crack initiated at the interface location of both sheets. Karim et al. [15] investigated different rivet coating included with frictional effects. The higher friction coefficient in coating provided higher strength in joints. Zhao et al. [16] investigated the shear strength of blind rivets using FEM and observed that the spacing between rivets affects the ultimate load bearing capacity. Jiang et al. [17] studied rivet joints with three different locking types for carbon fiber reinforced polymer (CFRP)/aluminum sheets. shear strength was affected by the locking type and suitable locking rivet should be selected for different joining applications. Cabrera-González et al. [18] studied rivet connections on composite materials in order to predict the stresses that may occur under different conditions. Ren et al. [19] used rivet-reinforced joints into tubular rivets for increasing energy absorption. In addition to static stresses, especially in the plates used in aviation, their dynamic response has great importance, and there are various data on the velocity and acceleration of dynamic behaviour in the literature. In this study, the stresses and dynamic responses that occur for the rivet connection of I-corner plates, which do not have enough data in the literature, have been examined.

\section{Model And Boundary Conditions}

Finite element method was used to examine the plates. This method, which is a numerical method, makes the solution more applicable by converting the geometric model to be examined into small elements. Solution precision depends on the number and structure of finite elements used. Therefore, a verification study has been carried out for the element structure and overall size.

The verification study model in Fig. 1 examines the axial tensile condition for a plate with a hole in the middle. The applied load is $\mathrm{P}=1000 \mathrm{~N}$ and steel $(\mathrm{E}=200 \mathrm{GPa}$ and

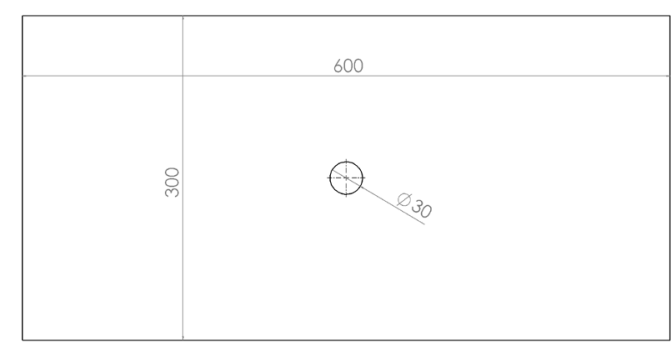

Figure 1. Axial loaded plate including a central hole poi $=0.3)$ material properties have been used in standard properties. Similar case studies and geometrical structures are available in various literature [20-24] studies. Stress concentration factor $(K)$ [25-26] for a plate containing a single hole under uni-axial tension is used for the state of stress and is given by

$$
K=\frac{\sigma_{\max }}{\sigma}
$$

The geometric model and dimensions created to examine the mechanical behaviour of L-corner plates are shown in Fig. 2. Two, three, four [27-28] and five [29] riveted joints are widely used between plate specimens. Two 1-corner plates are connected to each other with a total of 8 straight rivets under frictionless contact condition. The long part of the plates is $200 \mathrm{~mm}$ and the short part is $80 \mathrm{~mm}$ long. Its width is $40 \mathrm{~mm}$ and the thickness is 4 $\mathrm{mm}$. The hole diameter where the rivets are attached is 8 $\mathrm{mm}$. Structural static and dynamic analysis of the finite element model shown was used to examine the mechanical properties of rivet and plate behaviour. In the finite element model, Tet10 pyramid shaped finite elements were used for easier modelling of the curved geometries of the rivet heads. Tet 10 pyramid element contains a total of 10 points and provides a more precise solution because it is polynomial based rather than linear in the interpolation scheme. The element aspect ratio is 1 . Hex20 finite elements in rectangular prism structure were used in the modelling of the plates. The Hex 20 finite element with 8 corners has a total of 20 points and the interpolation is polynomial based. The aspect ratio is 2 on average and the average element quality is above $85 \%$. Material is defined with steel in standard properties. The results are given in the stress concentration factor. This factor is the ratio of the measured principal stress $\left(\sigma_{1}\right)$ to the normal bending stress and defined as;

$$
\mathbf{I}=\frac{\sigma_{1}}{\frac{M \cdot c}{I}}
$$

The stresses on rivets are illustrated with stress intensity factor and given for bending (case I) in Eq. 3 and tension (case II) in Eq. 4;

$$
\begin{aligned}
& \mathbf{I}_{\boldsymbol{r}}=\frac{\sigma_{1}}{\frac{(M / N) \cdot c}{I}} \\
& \mathbf{I}_{\boldsymbol{r}}=\frac{\sigma_{1}}{\frac{(F * l / N) \cdot c}{I}+\frac{(F / N)}{A}}
\end{aligned}
$$

For case I, the rivet stress intensity factor is the ratio of measured principal stress $\left(\sigma_{1}\right)$ to bending stress of one rivet in Eq. 3. $\mathrm{N}$ is the number of rivets, $\mathrm{I}$ is the second moment of inertia of rivet section, $\mathrm{A}$ is the rived cross-section area and $\mathrm{c}$ is the distance between rivet surface and rivet centre. For case II, moment effect is calculated from $F * l$ which defines applied force and the distance between rivet centre and force applied location. $l$ is the distance between force and rivet $\mathrm{Rv}_{1}$ centre $(0.065 \mathrm{~m})$.

The side surface of the bottom plate is fixed, and case 


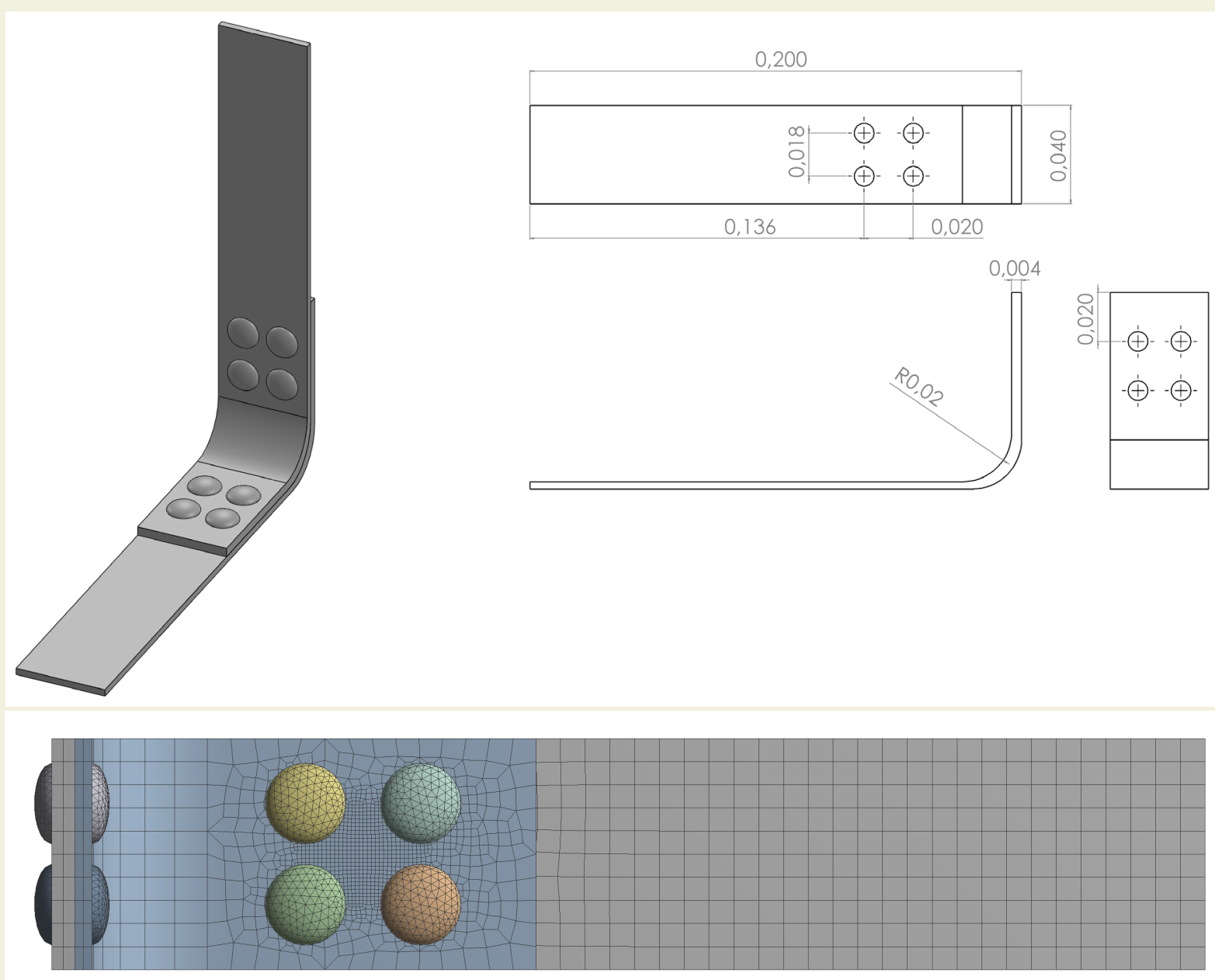

Figure 2. Geometrical and finite element model of I-plate connections

studies are made for static stress and deformation solutions under two different loading conditions. In the examinations, different pressure $(\mathrm{P})$ values were applied to the rounded bending surface of the 1 -plate and its effect on the stresses was shown. In the case I, a pure bending moment of $24 \mathrm{Nm}$, in the case II, a tensile force of $120 \mathrm{~N}$ was applied to the side surface with pressure.

The time interval used in the explicit analysis should reflect the dynamic behaviour, so the solution interval of

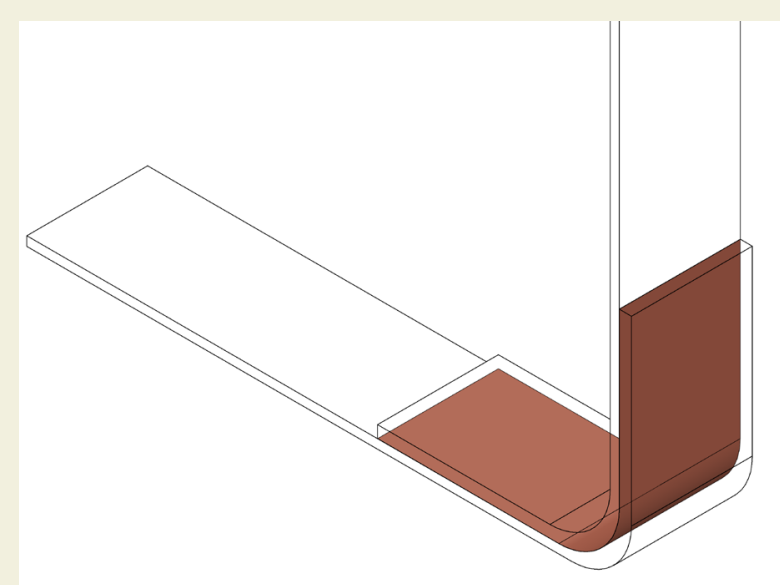

Figure 3. L-plates bonded with molten steel metal
$2 \mathrm{~ms}$ was used considering the computer load efficiency. Similar solution time is used in velocity and acceleration results [30-33] in dynamics studies. For the dynamic state, only $120 \mathrm{~N}$ tensile force was applied to the two surfaces where force and boundary conditions were applied in the plates. Fixed boundary condition is not included.

The model of the l-corner plate bonded with metal filler, which is a different type of connection, is shown in Fig. 3. The results of this connection type and rivet connection were compared for case II (axial loading). Instead of rivets, a $0.5 \mathrm{~mm}$ thick $(\mathrm{t})$ metal filler is attached between the $\mathrm{L}$-corner plates. The results are given as the stress intensity factor (Ir) in Eq. 5 for metal filler bonding. $t$ is thickness $(0.5 \mathrm{~mm})$ and $\mathrm{w}$ is width of plate $(10 \mathrm{~mm})$.

$$
\mathbf{I}_{r}=\frac{\sigma_{1}}{\frac{F}{t \times w}}
$$

\section{Results and Discussion}

Contour of stress concentration factor is shown for the perforated plate subjected to tension loading in Fig. 4. Stress concentration factor, $\mathrm{K}$ [25-26] is expressed as 3 in the literature and it was found as 3.0421 in this study. The finite element structure and model used were found to be suitable for stress analysis of L-plates. 




Figure 4. Stress concentration factor $(K)$ of finite element model of axial loaded plate including a central hole

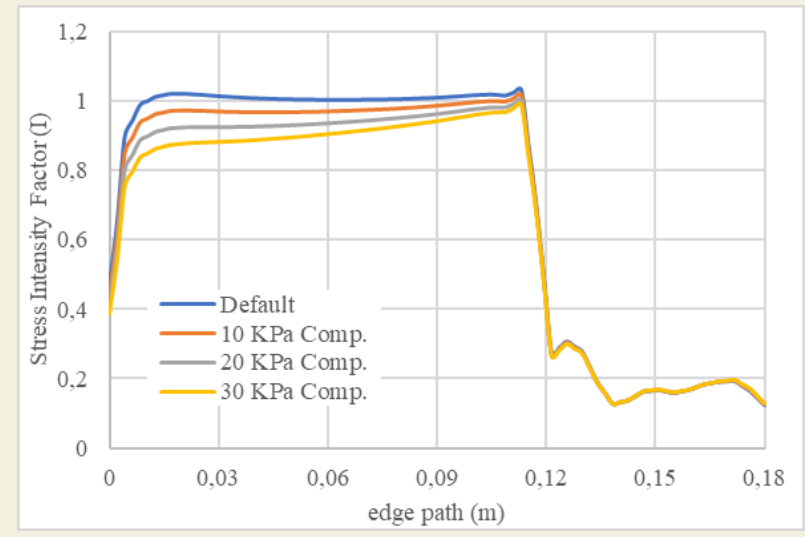

Figure 5. Stress intensity factor (I) on plate edge for bending

The results were taken from the path in the lower long edge of the bottom plate, and the stress intensity factor is shown in Fig. 5 for bending (case I). The effect of bending stress is expected to be approximately $\mathrm{I}=1$ when it does not produce a stress concentration. In the results, due to the support effect, the stress concentration factor started from a low value and suddenly increased to the value of 1 and remained almost constant until the section where the rivets are located. At the point where the other plate contacts $(x=0.116 \mathrm{~m})$, the stress intensity increased slightly as a result of the sharp corner effect and then suddenly decreased to 0.3 . In the region of the rivets, the stress concentration factor is on average $\mathrm{I}=0.2$. The increase in pressure applied to the rounding surface at the corner of the L-plate decreased the stress concentration except for the rivet region. The average stress concentration (I) at $10 \mathrm{kPa}, 20 \mathrm{kPa}$ and $30 \mathrm{kPa}$ of pressures was calculated as $0.96,0.92$ and 0.88 , respectively.

The vertical deformation of the plate edge for bending is shown in Fig. 6. As a result of the direction of the bending moment, the vertical deformation is upward, and the pressure applied to the rounding surface at the corner of the L-plate reduced the deformation. The effect of the moment formed as a result of axial tension (case II) on the stress intensity factor (I) is shown in Fig. 7. In contrast to the bending (case I), the pressure applied to the rounded surface did not cause a change in the stress concentration in the tensile (case II) results. The effect of applied pressure on stress concentration is negligible. Stress concentra-

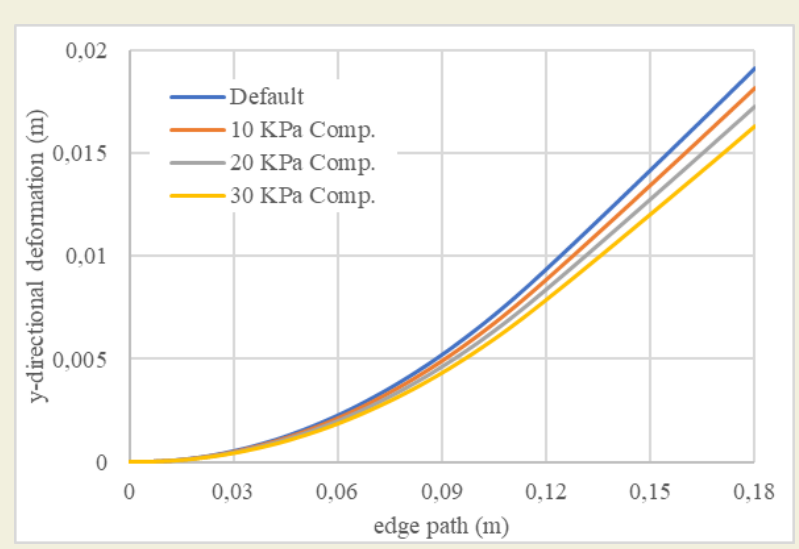

Figure 6. Vertical deflection of the plate edge for bending

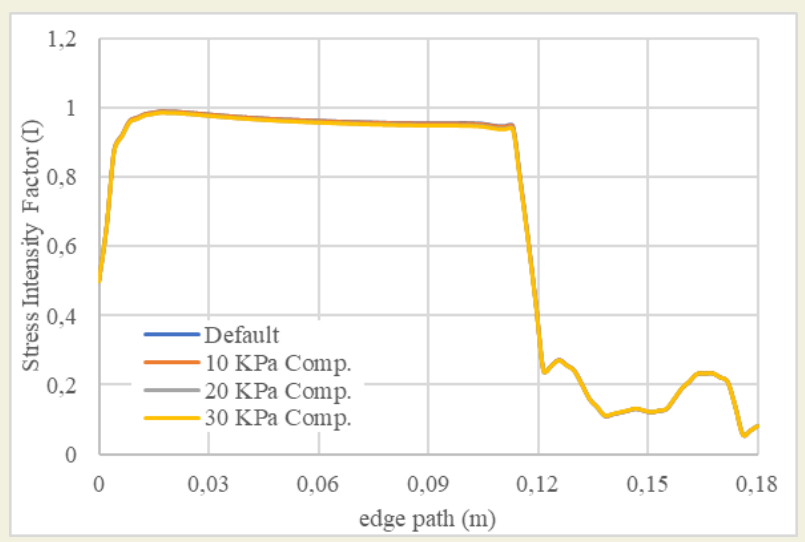

Figure 7. Stress intensity factor (I) on plate edge for axial loading

tion factors of case I and II are similar.

Vertical deformation results for tension (case II) are shown in Fig. 8. The applied pressure has reduced the deformation. The stresses formed on the surface of the rivet (Rv1) in contact with the plate hole are shown in Fig. 9 with the intensity factor $I_{r}$. The stress intensity factor in the bending (case I) is less affected by the applied pressure than in the tension (case II). However, the bending (case I) intensity factor values are higher than the tensile state (case II). The stress intensity factor was calculated to be $4.77,4.65,4.54$ and 4.42 for the bending condition (case I) and 4.34, 4.03, 3.72 and 3.41 for the axial tension condition (case II), respectively, according to the applied pressure.

The stress intensity in the bonding with filler and rivet connections was shown in Fig. 10. Although the stresses occurring in filler bonding were mostly lower than the stresses in rivets, they occurred at higher values due to the formation of folding behaviour where the plates were rolled. Using the multi-rivet connection is safer between the compared fasteners.

The effect of applied pressure for axial tensile condition is investigated for dynamic conditions. Tensile forces of $120 \mathrm{~N}$ were applied on a total of 2 surfaces where force and fixation boundary conditions were applied in dynamic condition. Velocity and acceleration values are shown 


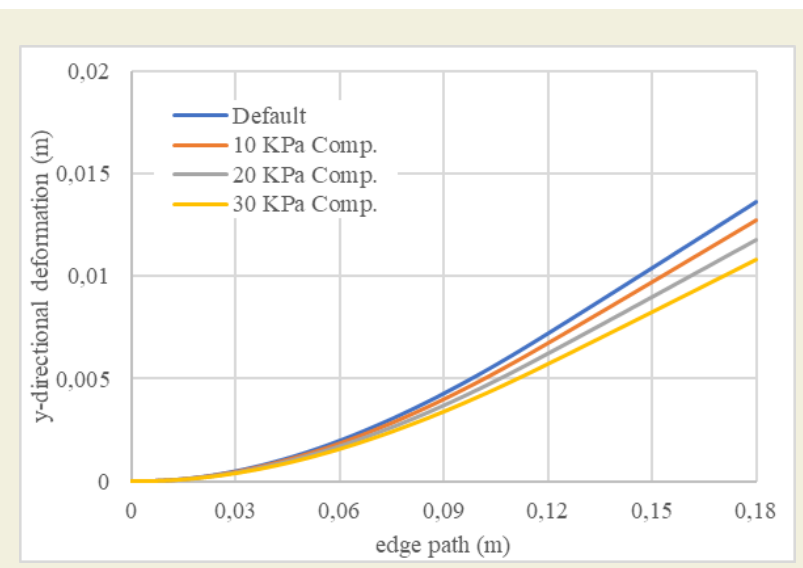

Figure 8. Vertical deflection of the plate edge for axial loading

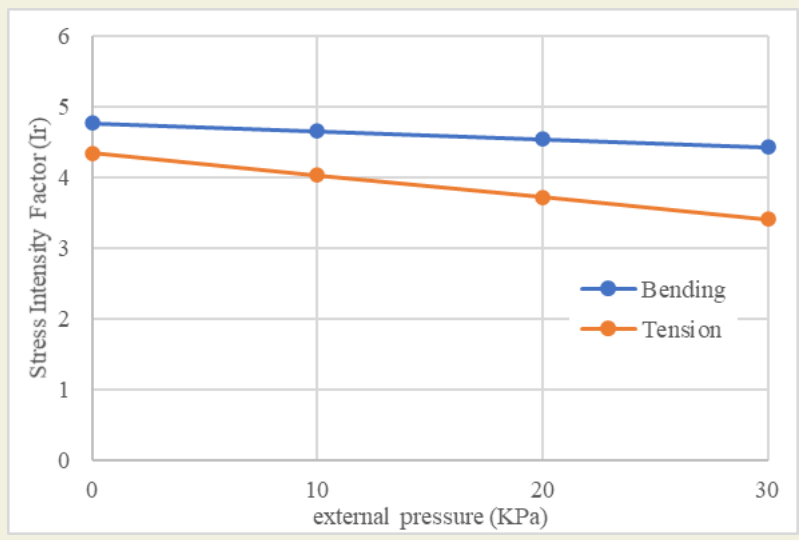

Figure 9. Stress intensity factor (Ir) on the rivet body for bending (I) and axial loading (II)



Figure 10. Stress intensity factor (Ir) on rivet and filler bonding for axial loading (case II)

on the Rv1 rivet to observe the behaviour in Fig. 11. As a result of multiple connection and contact effects, there are fluctuations in the results at certain intervals. The applied surface pressure caused the speed and acceleration values to decrease. The peak points in the instantaneous acceleration values decreased considerably with the applied pressure. However, the results of velocity values in the range of 0.00-0.02 $\mathrm{ms}$ are very close to each other.

The stress contours of the plates for bending (case I) and axial loading (case II) were shown in Table 1. Bending (case I) and axial loading (case II) conditions exhibited
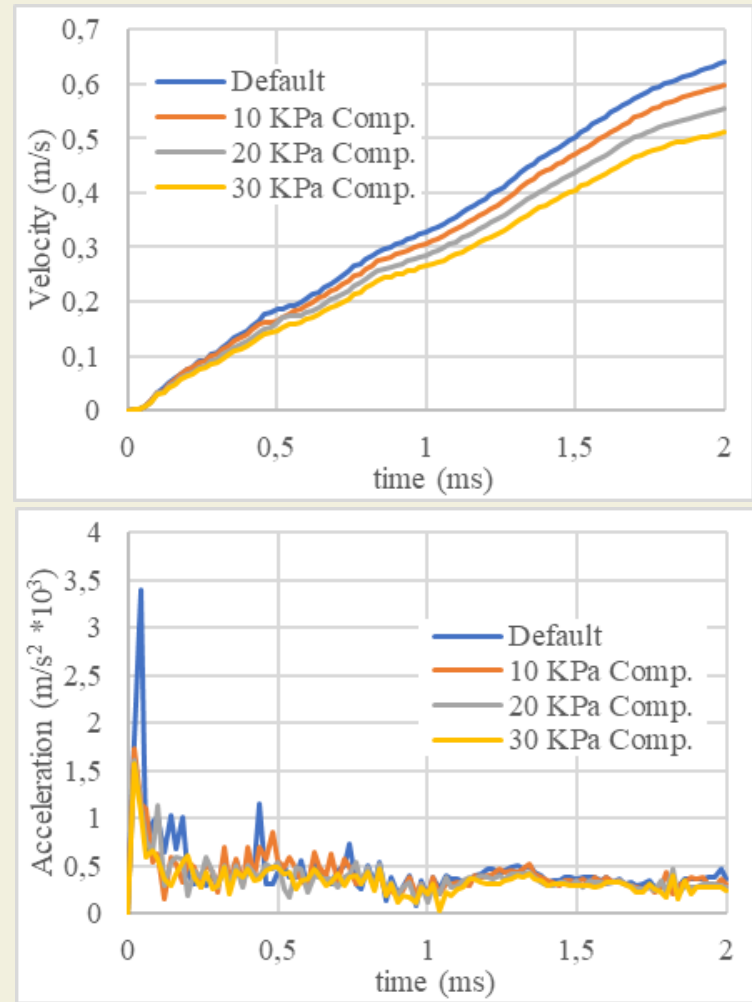

Figure 11. Total velocity and acceleration of the rivet for axial loading

different behaviour in the plates due to the fact that the plates contain l-corner shape. The bending effect (B.E) caused by bending (case I) in the lower and upper plates created an intense stress field in and around the vertical rivet holes of the plate. These stresses are absent in the case of axial loading (case II). The stresses are at the highest value due to fixed boundary condition applied at the fixing edge. The stresses formed a critical and widespread distribution, mostly around $70 \%$ of the highest contour values. Critical stresses (Cr.) occurring outside this region are marked in table 1 figures. There is a local stress concentration in the rivet socket where the Rv1 rivet contacts. In the case of bending (case I), the stresses in the lower and upper plates are close, while in axial loading (case II), the stresses in the lower plate are 2.5 times higher than the upper plate. It is seen that the bearing stresses (B.S) occur in the rivet beds of the lower and upper plates. Bearing stress contours (B.S) seen in vertical and horizontal rivet beds in the bending state (case I) were formed only in horizontal rivet beds in the axial stress state (case II). High stresses are seen on the inner edges of the rivet. In case of bending, a stress contour line is formed in the middle of the rivet. This can cause shear in the middle of the rivet. The applied pressure on rounded surface managed to reduce the stress values in both cases (cases I and II). The bending effect of the bending moment in the vertical part of the L-plate is seen in the difference between case I and case II. As a result of this bending effect, the rotation that occurs in the center axis of the rivets appears as a result of the case I rivet. In case of axial tension (case II), the rotation in the rivet principal axis is negligible. In both cases, there 


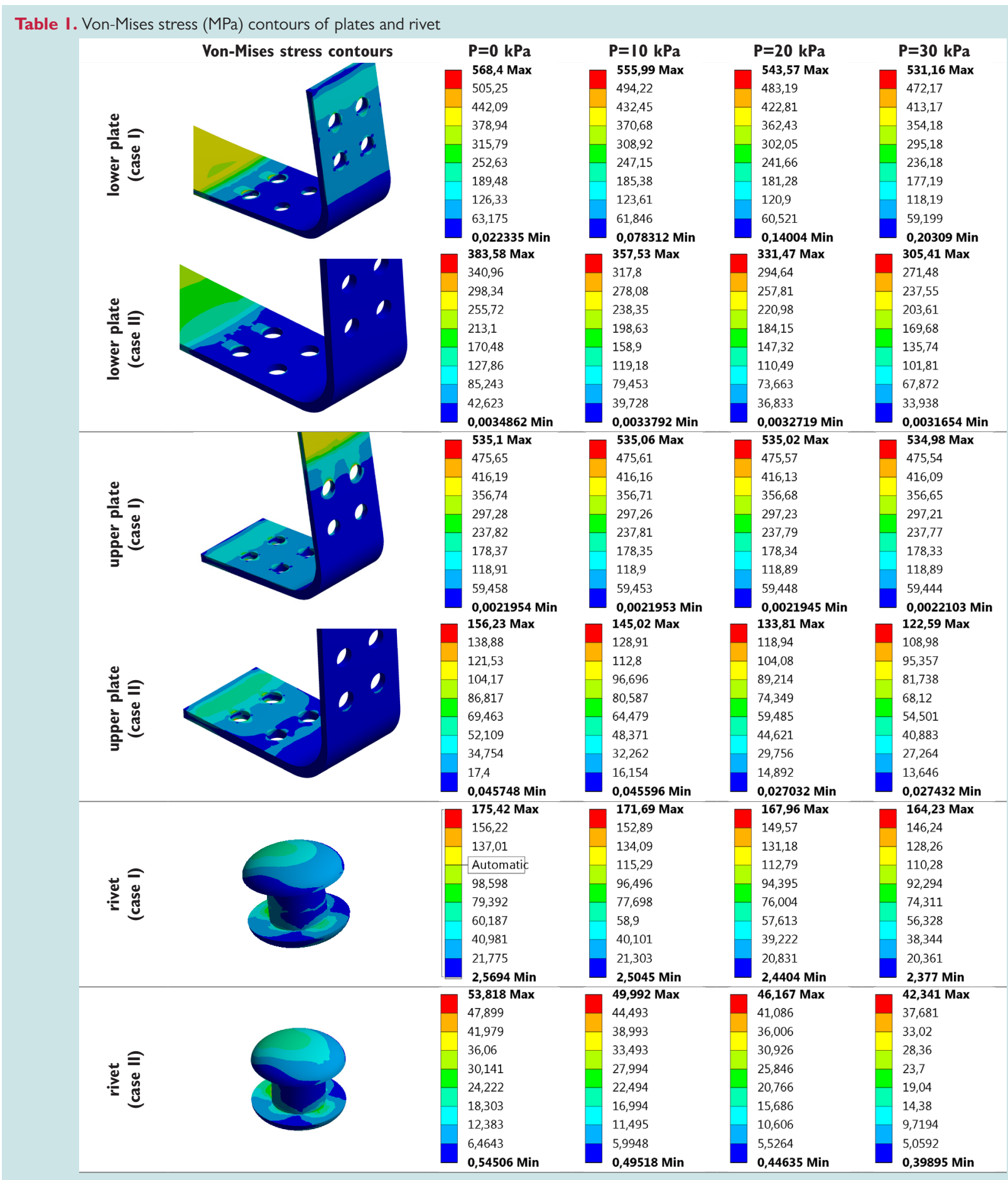

is no difference between the stress contours formed in the rivets due to the rotation effect.

\section{Conclusion}

The connection of 1-shape plates, which are widely used in aerospace and industrial applications, with rivets was investigated under bending and tension. In the examinations made using the finite element method, the results are shown separately for plate and rivet in the form of stress concentration factor. When the obtained findings are evaluated;

- Tension (case II) results are lower than bending (case I) results
- It has been observed that the stresses formed in the plate due to bending and tensile effects are equivalent to the calculated stresses and as a result the concentration factor is equal to 1

- The average stress concentration factor in the rivet region is $\mathrm{I}=0.2$

- The stress concentration factor $\left(\mathrm{I}_{\mathrm{r}}\right)$ is up to 5 in rivets

- The applied surface pressure decreased the stress intensity factor in bending except for the rivet region, but it was not effective in axial case

- It has been observed that critical stresses occur where bearing stresses occur, and this is more pronounced in 
the case of bending

- Although the contour distributions are similar, bending and rotation effects are observed in the upper part of the l-plate and the attached rivets in case of bending (case I)

- Applying pressure to the rounded surface reduces sharp accelerations in dynamic behaviour

- When the stress intensity in the fasteners was examined, the use of multi-rivet connection was safer than filler bonding in this case

\section{References}

[1] Moreno, J., Valiente, A. (2004). Stress intensity factors in riveted steel beams. Engineering Failure Analysis, 11: 777787.

[2] Ibrahim, R.A., Pettit, C.L. (2005). Uncertainties and dynamic problems of bolted joints and other fasteners. Journal of Sound and Vibration, 279: 857-936.

[3] Bedair, O.K., Eastaugh, G.F. (2007). A numerical model for analysis of riveted splice joints accounting for secondary bending and plates/rivet interaction. Thin-Walled Structures, 45: 251-258.

[4] Sadowski, T., Golewski, P., Zarzeka-Raczkowska, E. (2011). Damage and failure processes of hybrid joints: adhesive bonded aluminium plates reinforced by rivets. Computational Materials Science, 50: 1256-1262.

[5] D’Aniello, M., Portioli, F., Fiorino, L., Landolfo, R. (2011). Experimental investigation on shear behaviour of riveted connections in steel structures. Engineering Structures, 33: 516-531.

[6] Díaz, C., Martí, P., Victoria, M., Querin, O.M. (2011). Review on the modelling of joint behaviour in steel frames. Journal of Constructional Steel Research, 67: 741-758.

[7] Kumar, D.V.T.G.P., Naarayan, S.S., Sundaram, S.K., Chandra, S. (2012). Further numerical and experimental failure studies on single and multi-row riveted lap joints. Engineering Failure Analysis, 20: 9-24.

[8] Bedair, O. (2012). Stress field characteristics of eccentrically loaded aircraft spliced joints. Applied Mathematical Modelling, 36: 4543-4556,

[9] Huang, Z., Xue, S., Lai, J., Xia, L., Zhan, J. (2014). Self-piercing riveting with inner flange pipe rivet. Procedia Engineering, 81: 2042 - 2047

[10] Skorupa, M., Machniewicz, T., Skorupa, A., Korbel, A. (2015). Fatigue strength reduction factors at rivet holes for aircraft fuselage lap joints. International Journal of Fatigue, 80: 417- 425 .

[11] Kafie-Martinez, J., Keating, P.B., Chakra-Varthy, P., Correia, J., Jesus, A. (2018). Stress distributions and crack growth in riveted lap joints fastening thick steel plates. Engineering Failure Analysis, 91: 370-381.

[12] Song, L., Yan, W., Yu, C., Xie, Z., Tan, Q. (2019). Flexural behavior investigation of the cfs truss beams with self-piercing riveted connection. Journal of Constructional Steel Research, 156: 28-45.

[13] Nejad, R.M., Tohidi, M., Darbandi, A.J., Saber, A., Shariati,
M. (2020). Experimental and numerical investigation of fatigue crack growth behavior and optimizing fatigue life of riveted joints in al-alloy 2024 plates. Theoretical and Applied Fracture Mechanics, 108: 102669.

[14] Zhang, X., He, X., Wei, W., Lu, J., Zeng, K. (2020). Fatigue characterization and crack propagation mechanism of self-piercing riveted joints in titanium plates. International Journal of Fatigue, 134: 105465.

[15] Karim, M.A., Jeong, T., Noh, W., Park, K., Kam, D., Kim, C., Nam, D., Jung, H., Park, Y. (2020). Joint quality of self-piercing riveting (spr) and mechanical behavior under the frictional effect of various rivet coatings. Journal of Manufacturing Processes, 58: 466-477.

[16] Zhao, J., Peng, Y., Su, W., Dong, J. (2021). Finite element analysis of the shear capacity of stainless-steel blind-rivet connections. Journal of Constructional Steel Research, 179: 106558.

[17] Jiang, H., Zeng, C., Li, G., Cui, J. (2021). Effect of locking mode on mechanical properties and failure behavior of CFRP/Al electromagnetic riveted joint. Composite Structures, 257: 113162.

[18] Cabrera-González, J.A., Vargas-Silva, G., Barroso, A. (2021). Riveted joints in composites, a practical tool to estimate stresses around the rivet hole. Composite Structures, 263: 113735.

[19] Ren, X., Chen, C., Ran, X., Gao, X., Gao, Y. (2021). Investigation on lightweight performance of tubular rivet-reinforced joints for joining AA5052 sheets. Journal of the Brazilian Society of Mechanical Sciences and Engineering, 43(333): 1-13.

[20] Može, P., Beg, D. (2014). A complete study of bearing stress in single bolt connections. Journal of Constructional Steel Research, 95: 126-140.

[21] Salih, E.L., Gardner, L., Nethercot, D.A. (2010). Numerical investigation of net section failure in stainless steel bolted connections. J Construct Steel Res, 66(12): 1455-1466.

[22] Salih, E.L., Gardner, L., Nethercot, D.A. (2011). Bearing failure in stainless steel bolted connections. Engineering Structures, 33: 549-562.

[23] Liu, R., Feng, Z., Ye, H., Liu, Y. (2020). Stress redistribution of headed stud connectors subjected to constant shear force. International Journal of Steel Structures, 20(2): 436-451.

[24] Hu, Z., Delfanian, F. (2005). Stress concentration in laminated composites with a central circular hole under biaxial load. Proceedings of IMECE2005, ASME International Mechanical Engineering Congress and Exposition, Orlando, Florida USA.

[25] Pilkey, W.D. (1997). Peterson's stress concentration factors. 2nd ed., Wiley-Interscience, New York.

[26] Young, W.C., Budynas, R.G. (2002). Roark's formulas for stress and strain. Seventh Edition, McGraw-Hill.

[27] Senguttuvan, N., Lillymercy, J. (2015). Joint Strength analysis of single lap joint in glass fiber composite material. International Journal of Applied Engineering Research, 10(7): 16535-16545.

[28] Yan, W., Xie, Z., Yu, C., Song, L., He, H. (2017). Experimental investigation and design method for the shear strength of self-piercing rivet connections in thin-walled steel struc- 
tures. Journal of Constructional Steel Research, 133: 231240.

[29] Sadowski, T., Golewski, P., Zarzeka-Raczkowska, E. (2011). Damage and failure processes of hybrid joints: adhesive bonded aluminium plates reinforced by rivets. Computational Materials Science, 50: 1256-1262.

[30] Lacher, A., Jüngel, N., Wagner, U., Bager, A. (2012). Analytical calculation of in-plane response of plates with concentrated masses to impact and application to pyroshock simulation. Journal of Sound and Vibration, 331: 3358-3370.

[31] Alisjahbana, S.W., Wangsadinata, W. (2011). Response of damped orthotropic stiffened plates subjected to a stepped triangular blast loading. Procedia Engineering, 14: 989-996.

[32] Wang, Z., Liang, X., Liu, G. (2013). An analytical method for evaluating the dynamic response of plates subjected to underwater shock employing mindlin plate theory and laplace transforms. Mathematical Problems in Engineering, Article ID 803609: 1-11.

[33] Sansalone, M., Carino, N.J. (1987). Transient impact response of plates containing flaws. Journal of Research of the National Bureau of Standards, 92(6): 369-381. 